\title{
ALVEOLAR GAS TENSIONS, PULMONARY VENTILATION AND BLOOD PH DURING PHYSIOLOGIC SLEEP IN NORMAL SUBJECTS ${ }^{1}$
}

\author{
By EUGENE D. ROBIN, ROBERT D. WHALEY, CHARLES H. CRUMP, AND \\ DAVID M. TRAVIS \\ (From the Department of Medicine, Harvard Medical School and the Medical Clinics of the \\ Peter Bent Brigham Hospital, Boston, Mass.)
}

(Submitted for publication January 23, 1958; accepted March 20, 1958)

An increase in alveolar $\mathrm{CO}_{2}$ tension has been reported to accompany normal sleep $(1,2)$. The study of gas tensions during sleep has, however, been limited by two factors:

1) No accurate method of breath-to-breath analysis has been available, so that only spot checks of alveolar $\mathrm{CO}_{2}$ tensions have been used to compare waking with sleeping levels.

2) Procedures for obtaining alveolar or arterial samples have been disturbing to the subjects. It has not been possible, therefore, to study deep sleep by these methods.

The use of a rapid acting infrared $\mathrm{CO}_{2}$ spectrophotometer has circumvented both of these limitations and permitted an accurate and continuous study of the alveolar $\mathrm{CO}_{2}$ changes that occur during sleep.

This paper will deal with the magnitude and mechanism of $\mathrm{CO}_{2}$ retention during sleep, and with the changes that occur in pulmonary ventilation, respiratory gas exchange, mechanics of breathing and blood $\mathrm{pH}$.

\section{METHODS}

Each subject reported to the laboratory late in the evening without special preparation. A comfortable bed in a dark environment was provided. The necessary manipulations for a control series of measurements (see below) were carried out. The subject was then allowed to fall asleep. No sedative drugs were used. All observations were made with the subject in approximately the same body position. During the course of each study, the depth of sleep as judged by degree of consciousness, amount of motion and response to stimuli was frequently recorded.

A tight-fitting face mask was used for the administration and collection of gas. The mask was attached to a

\footnotetext{
1 This investigation was supported in part by a research grant (H-2243) from the National Heart Institute of the National Institutes of Health, Public Health Service, and in part by a grant from the Massachusetts Heart Association.
}

low resistance valve with a small dead space. The arrangement was comfortable enough so that most subjects were able to sleep with the mask in place. During collection periods the system was frequently checked for leaks.

Expired air was collected in Douglas bags and the volume measured in a Tissot spirometer.

Alveolar $\mathrm{CO}_{2}$ tensions were measured with a rapid acting infrared $\mathrm{CO}_{2}$ analyzer. It has been shown by Collier, Affeldt and Farr (3) and verified by our group that in subjects without pulmonary disease, the peak end tidal $\mathrm{CO}_{2}$ tension measured by this apparatus is equal (plus or minus $2 \mathrm{~mm} . \mathrm{Hg}$ ) to arterial $\mathrm{CO}_{2}$ tension. This technique provided a breath-to-breath measurement of alveolar $\mathrm{CO}_{2}$ tension without distraction or discomfort to the subject. $\mathrm{CO}_{2}$ concentrations in expired air were measured by the same apparatus.

The oxygen concentrations in expired air samples were measured with a Pauling oxygen analyzer.

The volume of alveolar ventilation was calculated by the Bohr equation (4). Oxygen consumption, $\mathrm{CO}_{2}$ production, alveolar oxygen tension, and the expiratory exchange ratio were calculated by standard methods $(5,6)$.

The ventilatory response to $\mathrm{CO}_{2}$ was tested by the administration of $\mathrm{CO}_{2}$ mixtures. Each mixture was administered for at least fifteen minutes before expired air was collected. The response to $\mathrm{CO}_{2}$ was expressed as the ratio of the increment in alveolar ventilation to the increment in alveolar $\mathrm{CO}_{2}$.

Appropriate vessels were intubated with No. 18 polyvinyl catheters for the collection of blood. The catheter was filled with sodium-heparin solution diluted 1 to 10 with normal saline. Between periods of blood withdrawal, a sterile cap was placed on the catheter. In this manner blood could be obtained without disturbing or waking the subjects.

Blood $\mathrm{pH}$ was measured by means of a Beckman $\mathrm{pH}$ meter. Readings were made at room temperature and converted to body temperature by the Rosenthal correction factor (7).

The oxygen content and saturation of arterial blood were determined by the technique of Van Slyke and Neill (8).

The mechanics of breathing during the waking and sleeping states were studied by measurements of pulmonary compliance and mean airway resistance. ${ }^{2}$ These

\footnotetext{
2 These measurements were made by Dr. Roe E. Wells.
} 


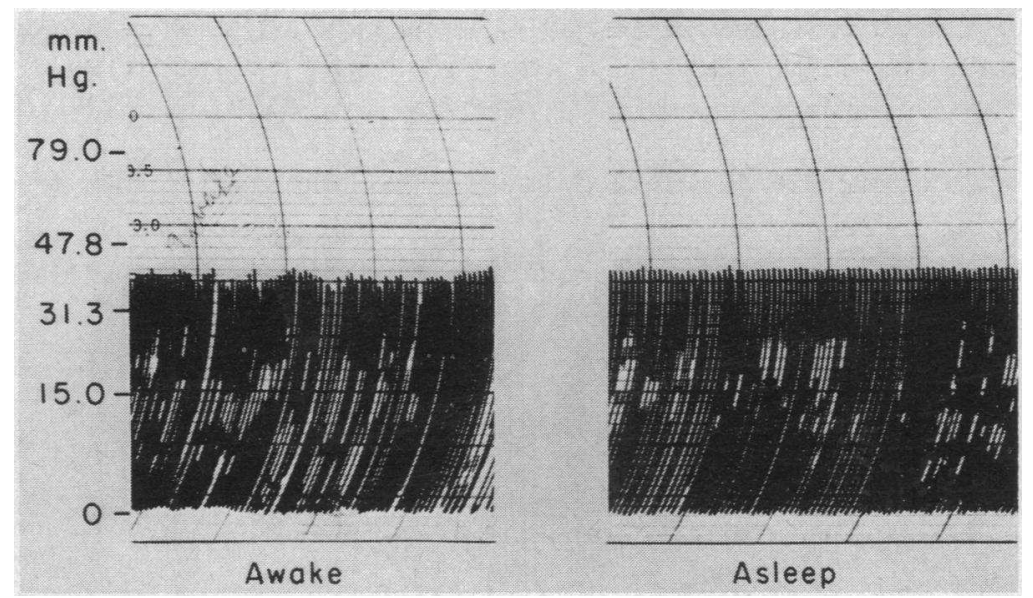

Fig. 1. A Comparison of the Breath-to-Breath Variation of Alveolar Carbon Dioxide Tension During the Waking and Sleeping States

measurements were made by the technique of Mead and Whittenberger (9). An intraesophageal balloon was used for the measurement of intrathoracic pressure. These studies were performed with the subject in the right lateral decubitus position awake and asleep.

Using these methods, breath-to-breath alveolar $\mathrm{CO}_{\text {: }}$ tensions were obtained before and during sleep in 14 normal males. For comparison, 6 normal males were kept fully awake during the night and hourly alveolar $\mathrm{CO}_{2}$ tensions were determined.

The ventilatory response to $\mathrm{CO}_{2}$, awake and asleep, was tested in 10 subjects.

In three subjects arterial blood $\mathrm{pH}$ was determined and in two of these subjects venous $\mathrm{pH}$ was determined simultaneously. A consistent difference between arterial and venous $\mathrm{pH}$ was observed in the sixteen samples studied in this way. Therefore, the $\mathrm{pH}$ studies made on four additional subjects were carried out on venous blood only to obviate the necessity of an indwelling arterial

TABLE I

A comparison of alveolar carbon dioxide tension awake and one hour after the onset of sleep

\begin{tabular}{|c|c|c|}
\hline \multirow[b]{2}{*}{ Subject } & \multicolumn{2}{|c|}{$\begin{array}{l}\text { Alveolar carbon dioxide tensior } \\
\mathrm{mm} . \mathrm{Hg}\end{array}$} \\
\hline & Awake & Asleep \\
\hline $\begin{array}{l}\text { R. W. } \\
\text { A. G. } \\
\text { J. M. } \\
\text { J. S. } \\
\text { J. A. } \\
\text { R. C. } \\
\text { R. W. } \\
\text { R. R. } \\
\text { L. S. } \\
\text { O. B. } \\
\text { E. R. }\end{array}$ & $\begin{array}{l}41 \\
37 \\
41 \\
38 \\
42 \\
43 \\
40 \\
40 \\
42 \\
43 \\
44\end{array}$ & $\begin{array}{l}44 \\
41 \\
47 \\
40 \\
46 \\
45 \\
41 \\
45 \\
45 \\
47 \\
49\end{array}$ \\
\hline Mean & $\begin{array}{r}41.0 \\
\mathrm{p}<0.001\end{array}$ & 44.6 \\
\hline
\end{tabular}

catheter. Arterial oxygen saturations were determined in two subjects.

Pulmonary compliance and mean airway resistance studies were carried out in three subjects.

\section{RESULTS}

The changes that occurred with sleep may be considered under the following categories :

1) The breath-to-breath variation of alveolar $\mathrm{CO}_{2}$.

2) The level of alveolar $\mathrm{CO}_{2}$ tension.

3) Alveolar oxygen tension and arterial oxygen saturation.

4) Total ventilation, alveolar ventilation, oxygen consumption, $\mathrm{CO}_{2}$ production and respiratory exchange ratio.

5) Ventilatory response to $\mathrm{CO}_{2}$.

6) Blood $p H$.

7) Mechanics of breathing.

8) Rhythm of respiration.

Changes in breath-to-breath variation of alveolar $\mathrm{CO}_{2}$ tension

An analysis of variance (10) was performed on the breath-to-breath variation of alveolar $\mathrm{CO}_{2}$ tension in four representative subjects comparing a two minute period during the waking state with a similar period during the sleeping state.

During the waking state there was a mean breath-to-breath variation of alveolar $\mathrm{CO}_{2}$ tension of $0.8 \mathrm{~mm}$. $\mathrm{Hg}$. Such variation reflects changes in both metabolism and in the control of ventilation. 


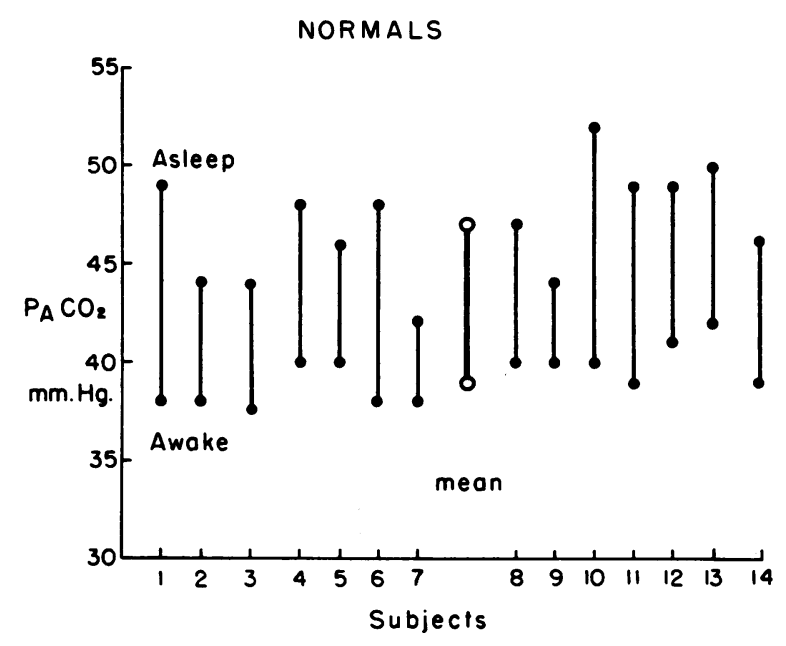

Fig. 2. Peak Alveolar Carbon Dioxide Tensions During Sleep

During sleep these fluctuations virtually vanished. The mean breath-to-breath variation fell to $0.2 \mathrm{~mm}$. $\mathrm{Hg}$. An example of this stabilization of respiration is shown in Figure 1. The peak end tidal value of $\mathrm{CO}_{2}$ during each breath is equal to alveolar $\mathrm{CO}_{2}$ tension. The stability of alveolar $\mathrm{CO}_{2}$ tension during sleep is obvious. The appearance of such stable respiration is a characteristic change that occurs with the onset of sleep. Its time of appearance correlates well with electroencephalographic changes indicating sleep (11).

\section{Changes in the level of alveolar $\mathrm{CO}_{2}$ tension}

The infrared $\mathrm{CO}_{2}$ analyzer provided about 7,000 measurements of alveolar $\mathrm{CO}_{2}$ tension during each study. It is obviously not practical to report the complete data from each subject. To define the magnitude of the changes in alveolar $\mathrm{CO}_{2}$ tension during sleep, three selected groups of data are presented :

a) A comparison of the average waking alveolar $\mathrm{CO}_{2}$ tension with the average alveolar $\mathrm{CO}_{2}$ tension after one hour of sleep. These data were obtained by averaging the breath-to-breath values of alveolar $\mathrm{CO}_{2}$ tension during a two minute period while each subject was awake, and during a two minute period after the subject had been asleep for one hour. These data are shown in Table I. The mean increase in $\mathrm{CO}_{2}$ tension after one hour of sleep is $3.6 \mathrm{~mm}$. $\mathrm{Hg}$. This is a highly significant change. b) A comparison of the average waking alveolar $\mathrm{CO}_{2}$ tension with the highest alveolar $\mathrm{CO}_{2}$ tension attained and maintained for at least four consecutive breaths during sleep. The peak value obtained from four consecutive breaths insured that falsely high values produced by breath-holding would not be included. These data are shown in Figure 2, and it can be seen that the peak increase may be as high as $14 \mathrm{~mm}$. $\mathrm{Hg}$ (Subject 10). The mean peak increase for the group is $9 \mathrm{~mm}$. $\mathrm{Hg}$ which is a highly significant change.

c) Data illustrating the pattern of $\mathrm{CO}_{2}$ increase during several hours of sleep. These data, obtained from three normal subjects, are shown in Figure 3. Alveolar $\mathrm{CO}_{2}$ tensions are plotted along the ordinate and time in hours, along the abscissa. The straight lines connecting points indicate that continual $\mathrm{CO}_{2}$ analysis was performed but only hourly measurements were charted. These data show considerable variation, apparently changing with the level of consciousness of the subject, but the values are higher during sleep than during waking. The peak rise in alveolar $\mathrm{CO}_{2}$ tension tended to develop within the first one to two hours of sleep. This is consistent with the general belief that this period represents the time of deepest sleep (2).

These data from sleeping subjects may be com-

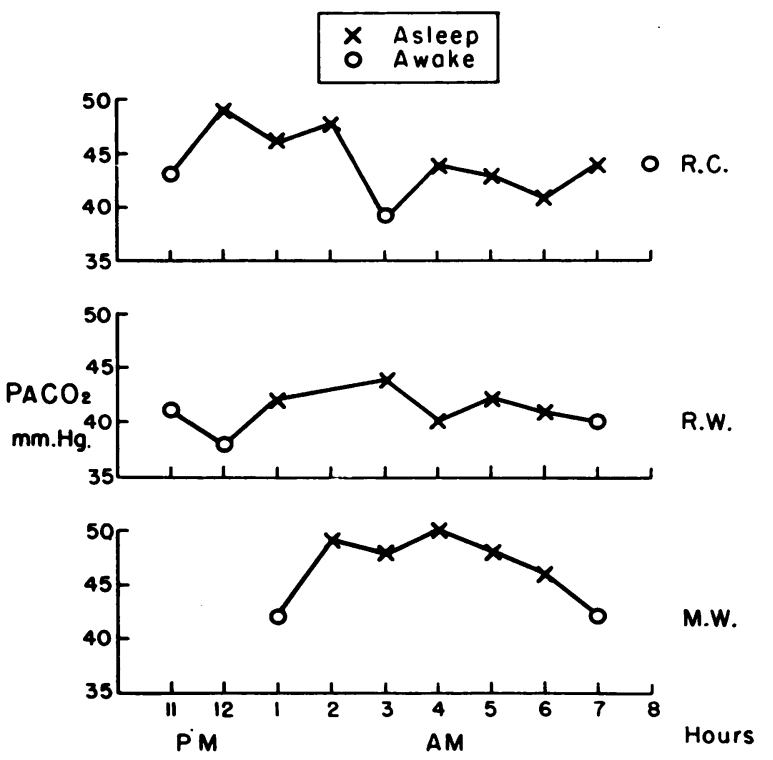

Fig. 3. Hourly Changes in Alveolar Carbon Dioxide Tension in Three Normal Subjects 

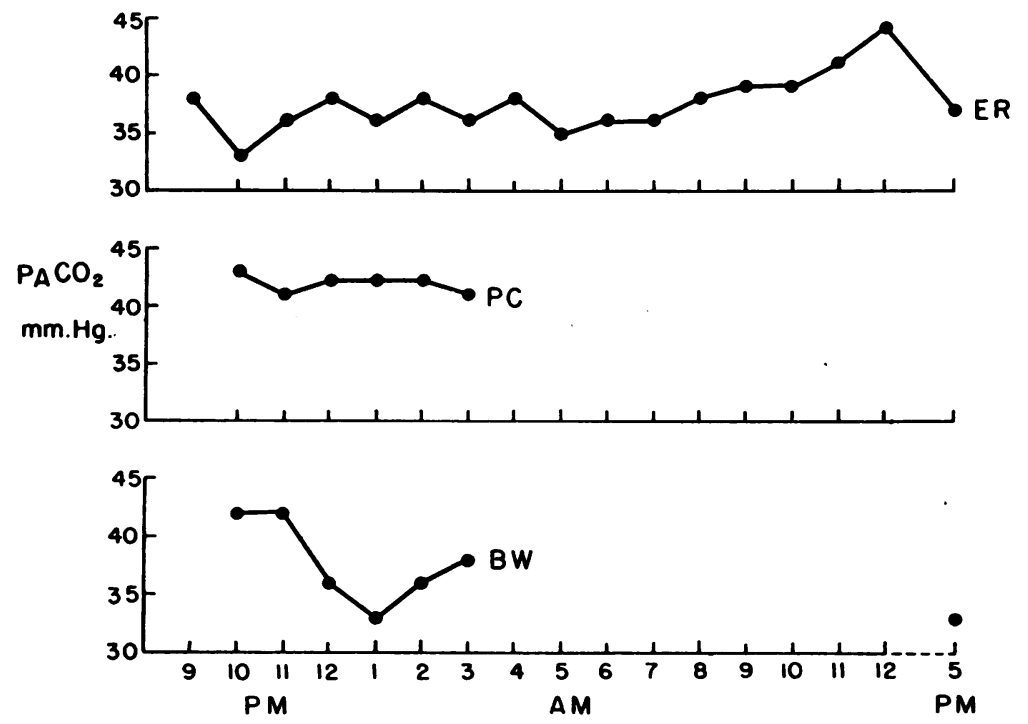

Fig. 4. Hourly Changes in Alveolar Carbon Dioxide Tension in Waking Normals at Night

pared with those shown in Figure 4. These data are taken from three normal subjects, awake and fully conscious during a given night of study. It can be seen that alveolar $\mathrm{CO}_{2}$ tension in the nonsleeping subjects does not increase consistently during the night. This finding indicates that there is no normal diurnal cycle of alveolar $\mathrm{CO}_{2}$ tension independent of sleep.

\section{Changes in alveolar oxygen tension and arterial oxygen saturation}

The data in Table II demonstrate a mean decrease in alveolar oxygen tension of $3 \mathrm{~mm}$. $\mathrm{Hg}$ during sleep. This decrease is not statistically

TABLE II

A comparison of alveolar oxygen tension awake and asleep

\begin{tabular}{lcc}
\hline & \multicolumn{2}{c}{ Alveolar oxygen tension } \\
\cline { 2 - 3 } Subject & Awake & Asleep \\
\hline A. G. & 101 & 106 \\
J. S. & 109 & 109 \\
J. A. & 107 & 104 \\
R. C. & 106 & 106 \\
R. W. & 113 & 111 \\
R. R. & 122 & 111 \\
L.S. & 105 & 100 \\
O. B. & 105 & 92 \\
Mean & 108.4 & 104.9 \\
& $\mathrm{p}>0.20$ & \\
\hline
\end{tabular}

significant. ${ }^{3}$ The arterial oxygen saturations during sleep, shown in Table III, confirm the absence of arterial unsaturation during sleep.

Changes in total ventilation, alveolar ventilation, oxygen consumption, $\mathrm{CO}_{2}$ production and respiratory exchange ratio

Changes in total and alveolar ventilation, oxygen consumption, $\mathrm{CO}_{2}$ production and respiratory exchange ratio during sleep are shown in Table

${ }^{3}$ Theoretically an increase in alveolar $\mathrm{CO}_{2}$ tension without a change in the respiratory exchange ratio will result in a fall in alveolar oxygen tension. Alveolar oxygen tensions were calculated from experimentally obtained alveolar $\mathrm{CO}_{2}$ tensions, expired $\mathrm{CO}_{2}$ concentration and inspired and expired oxygen concentrations. The failure to demonstrate a significant decrease in alveolar oxygen tension in the face of an increased alveolar $\mathrm{CO}_{2}$ tension probably is related to methodological problems. Oxygen analysis was performed by means of a Pauling oxygen analyzer which has an accuracy at best of plus or minus 1 per cent. Small errors in the determination of inspired and expired oxygen concentration will produce large errors in the calculation of respiratory exchange ratio. (This problem presumably accounts for the fact that a number of the respiratory exchange ratios shown in Table IV are greater than 1.00.) Since four separate experimental observations were necessary to calculate each alveolar oxygen tension, the inherent experimental error is obviously greater than would be expected if only a single measurement was required, as in the case of alveolar $\mathrm{CO}_{2}$ tension. 
IV. There is a mean decrease of $2.15 \mathrm{~L}$. per minute in total ventilation and a mean decrease of 1.66 L. per minute in alveolar ventilation. These changes are statistically significant. There is a mean decrease in oxygen consumption of $57 \mathrm{ml}$. per minute and a mean decrease in $\mathrm{CO}_{2}$ production of $79 \mathrm{ml}$. per minute during sleep. ${ }^{4}$ These changes are also statistically significant. The respiratory exchange ratio is not significantly different during sleep.

\section{Changes in the ventilatory response to $\mathrm{CO}_{2}$}

The data relating to change in the ventilatory response to $\mathrm{CO}_{2}$ are shown in Table V. During sleep there is a mean decrease of $1.05 \mathrm{~L}$. per minute of alveolar ventilation per $\mathrm{mm}$. $\mathrm{Hg}$ of alveolar $\mathrm{CO}_{2}$ tension. This is a highly significant decrease. The magnitude of this change is illustrated in Figure 5 , where waking and sleeping response curves from three representative studies are shown.

This depression of the ventilatory response to $\mathrm{CO}_{2}$ sets in rapidly when sleep develops and is rapidly reversed when waking occurs. This is demonstrated by the following qualitative observation. While asleep, breathing mixtures containing 4 to 6 per cent $\mathrm{CO}_{2}$ led to only moderate augmentation of ventilation. Subjects who awoke

${ }_{4}^{4} \mathrm{CO}_{2}$ production was measured in all 14 experimental subjects. Oxygen consumption was measured in 8 subjects.
TABLE III

A comparison of arterial oxygen saturation awake and asleep in two normal subjects

\begin{tabular}{ccc}
\hline \hline & \multicolumn{2}{c}{ Arterial oxygen saturation } \\
\cline { 3 - 3 } Subject & Awake & Asleep \\
\hline R. R. & 94 & 94 \\
L. S. & 96 & 95 \\
\hline
\end{tabular}

while breathing these mixtures showed a marked hyperventilation almost immediately after waking. Subjects remaining awake under these circumstances continued to hyperventilate profoundly. Subjects drifting back to sleep showed a subsidence of total ventilation to the previous sleeping level.

\section{Changes in blood $p H$}

The changes in $\mathrm{pH}$ during sleep were measured by taking samples of blood each hour since no method of continuous measurement of blood $\mathrm{pH}$ in humans is available. The mean value for waking and sleeping $\mathrm{pH}$ in each subject was obtained by averaging the values found during each state. These data are shown in Table VI and show a mean decrease of $0.03 \mathrm{pH}$ unit during sleep, a statistically significant change.

Data illustrating the pattern of $\mathrm{pH}$ changes during sleep are shown in Figure 6. Blood $\mathrm{pH}$ is

TABLE IV

A comparison of total ventilation, alveolar ventilation, oxygen consumption, carbon dioxide production and respiratory exchange ratio during the waking and sleeping states

\begin{tabular}{|c|c|c|c|c|c|c|c|c|c|c|}
\hline \multirow[b]{2}{*}{ Subject } & \multicolumn{2}{|c|}{ Total ventilation } & \multicolumn{2}{|c|}{ Alveolar ventilation } & \multicolumn{2}{|c|}{$\mathrm{O}_{2}$ consumption } & \multicolumn{2}{|c|}{$\mathrm{CO}_{2}$ production } & \multicolumn{2}{|c|}{$\begin{array}{l}\text { Respiratory } \\
\text { exchange ratio }\end{array}$} \\
\hline & Awake & Asleep & Awake & Asleep & Awake & Asleep & Awake & Asleep & Awake & Asleep \\
\hline & \multicolumn{2}{|c|}{ I./min. B.T.P.S. } & \multicolumn{2}{|c|}{ L./min. B.T.P.S. } & \multicolumn{2}{|c|}{$\operatorname{ml.} / \min . S . T . P . D}$. & \multicolumn{2}{|c|}{ ml./min. S.T.P.D. } & & \\
\hline R. W. & 7.69 & 5.45 & 5.08 & 2.72 & & & 233 & 146 & & \\
\hline A. $\mathrm{G}$. & 6.20 & 4.20 & 3.68 & 2.14 & 232 & 120 & 154 & 99 & 0.66 & 0.82 \\
\hline J. M. & 8.64 & 5.17 & 6.42 & 3.33 & & & 399 & 174 & & \\
\hline J.S. & 7.99 & 4.97 & 4.80 & 3.30 & 204 & 163 & 204 & 157 & 1.00 & 0.96 \\
\hline J. A. & 6.31 & 6.04 & 3.72 & 3.87 & 190 & 197 & 174 & 197 & 0.92 & 1.00 \\
\hline R. C. & 8.10 & 6.06 & 5.09 & 3.76 & 258 & 202 & 242 & 198 & 0.94 & 0.98 \\
\hline R. W. & 11.60 & 7.13 & 7.47 & 4.17 & 303 & 182 & 337 & 193 & 1.04 & 1.06 \\
\hline R. R. & 6.23 & 4.80 & 4.47 & 2.91 & 183 & 122 & 192 & 144 & 1.05 & 1.18 \\
\hline L. S. & 7.72 & 8.41 & 5.63 & 5.29 & 256 & 300 & 246 & 279 & 0.96 & 0.93 \\
\hline O. B. & 9.89 & 8.32 & 6.67 & 5.30 & 342 & 351 & 359 & 276 & 1.05 & 0.79 \\
\hline E. R. & 6.12 & 3.87 & 4.25 & 2.28 & & & 244 & 147 & & \\
\hline C. C. & 8.65 & 5.41 & & & 319 & 202 & 311 & 184 & 0.97 & 0.91 \\
\hline R. W. & 7.99 & 5.32 & & & 314 & 192 & 296 & 176 & 0.94 & 0.92 \\
\hline Mean & 7.93 & 5.78 & 5.21 & 3.55 & 260 & 203 & 261 & 182 & 0.95 & 0.96 \\
\hline $\mathrm{p}$ & \multicolumn{2}{|c|}{$<0.001$} & \multicolumn{2}{|c|}{$<0.001$} & \multicolumn{2}{|c|}{$<0.025>0.01$} & \multicolumn{2}{|c|}{$<0.05>0.005$} & \multicolumn{2}{|c|}{ not sig. } \\
\hline
\end{tabular}


TABLE $V$

A comparison of the ventilatory response to carbon dioxide during the waking and sleeping states

\begin{tabular}{ccc}
\hline \hline & \multicolumn{2}{c}{$\Delta$ Alveolar ventilation } \\
\cline { 2 - 3 } Subject & Awake & Asleep \\
\hline & L./min./mm. $\mathrm{Hg}_{\text {CO }}$ tension \\
R. W. & 3.30 & 0.13 \\
A. G. & 1.32 & 0.57 \\
J. M. & 2.03 & 0.43 \\
J.S. & 0.65 & 0.22 \\
J. A. & 0.94 & 0.46 \\
R. C. & 1.09 & 0.72 \\
R. R. & 0.79 & 0.45 \\
L.S. & 1.30 & 0.33 \\
O. B. & 0.75 & 0.04 \\
E. R. & 1.88 & 0.12 \\
Mean & 1.40 & 0.35 \\
p & \multicolumn{2}{c}{$<0.001$} \\
\hline
\end{tabular}

plotted along the ordinate and time in hours, along the abscissa. It can be seen that blood $\mathrm{pH}$ tends to fall during sleep. The decrease in $\mathrm{pH}$, however, is not present as consistently as is the rise in alveolar $\mathrm{CO}_{2}$ tension.

\section{Mechanics of breathing}

The effect of sleep on pulmonary compliance and mean airway resistance is shown in Table VII. There are small and probably insignificant changes in pulmonary compliance while airway resistance showed a small but consistent decrease during sleep. The number of subjects studied is not large enough to permit statistical analysis for significance. However, these data indicate that sleep
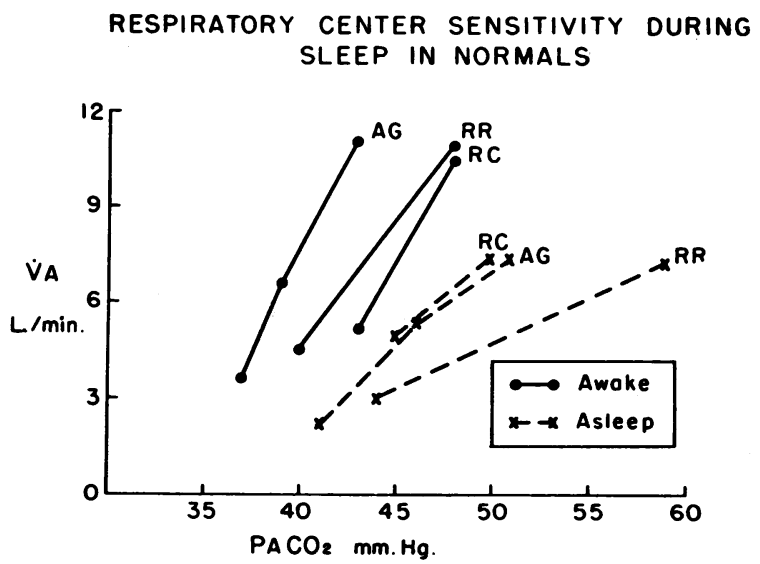

Fig. 5. Waking and Sleeping Ventilatory Response to Carbon Dioxide in Three Normal Subjects
TABLE VI

A comparison of blood $\mathrm{pH}$ during the waking and sleeping states

\begin{tabular}{llcc}
\hline & & \multicolumn{2}{c}{ Average blood $\mathrm{pH}$} \\
\cline { 3 - 4 } Subject & Source & Awake & Asleep \\
\hline L. T. & Artery & 7.43 & 7.42 \\
M. W. & Artery & 7.40 & 7.37 \\
M. P. & Artery & 7.45 & 7.41 \\
P. N. & Vein & 7.44 & 7.41 \\
T. A. & Vein & 7.46 & 7.41 \\
M. P. & Vein & 7.41 & 7.37 \\
R. R. & Vein & 7.42 & 7.40 \\
Mean & & 7.43 & 7.40 \\
& & &
\end{tabular}

does not produce an increase in airway resistance or a decrease in pulmonary compliance. Thus the work of breathing, if anything, is less during sleep than in the waking state.

\section{Khythm of respiration}

Six of 14 normal subjects showed cyclic breathing of the Cheyne-Stokes variety during sleep. These variations in the rhythm of breathing differed from true Cheyne-Stokes breathing in that
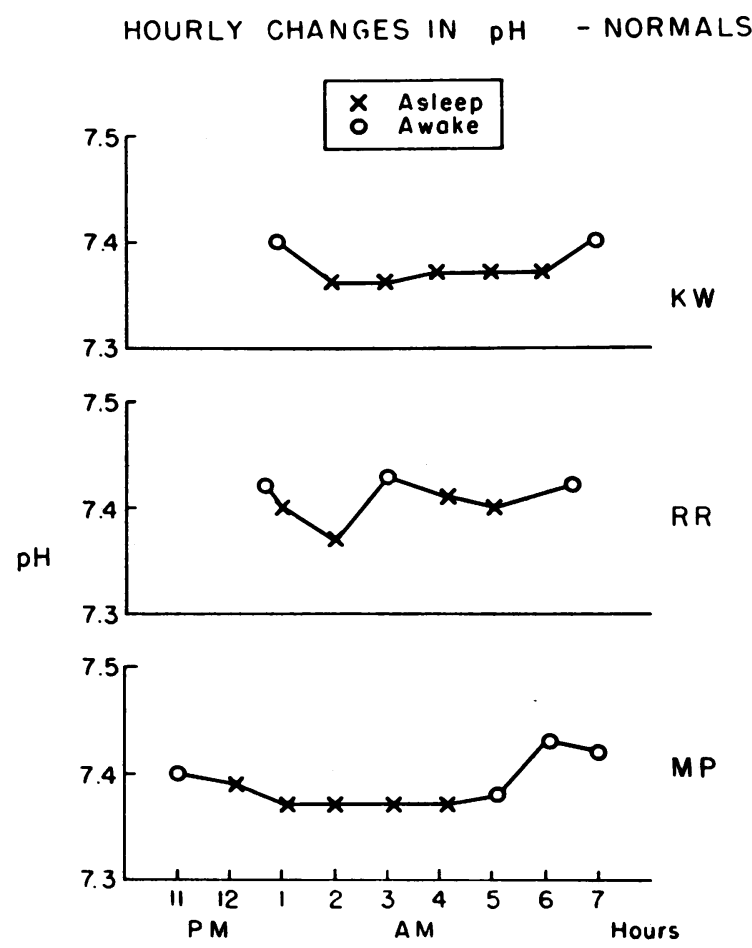

Fig. 6. Hourly Changes in Blood pH in Three Normal Subjects 
periods of hyperventilation alternated with hypopnea rather than with apnea. In normal subjects periodic breathing was only found transiently. No subject demonstrated this variety of breathing longer than one hour during a night of sleep. An example of this phenomenon is shown in Figure 7.

\section{DISCUSSION}

The increase in alveolar $\mathrm{CO}_{2}$ tension during sleep is a consistent finding. Alveolar $\mathrm{CO}_{2}$ tension may be increased by either of two mechanisms :

1) An increase in $\mathrm{CO}_{2}$ production.

2) A decrease in alveolar ventilation.

Since the data show that sleep is accompanied by a decrease rather than an increase in $\mathrm{CO}_{2}$ production, the $\mathrm{CO}_{2}$ retention of sleep is to be explained by a decrease in alveolar ventilation. This decrease in alveolar ventilation is apparently related to a depression of respiratory center sensitivity to $\mathrm{CO}_{2}$. This is indicated by the marked decrease in the ventilatory response to $\mathrm{CO}_{2}$ observed during sleep.

The ventilatory response to $\mathrm{CO}_{2}$ may be accepted, with some reservations, as a quantitative expression of respiratory center sensitivity to $\mathrm{CO}_{2}$ $(12,13)$. The reservations are as follows:

1) Inhaled $\mathrm{CO}_{2}$ stimulates the peripheral chemoreceptors in the aortic and carotid bodies as well as the medullary chemoreceptors (14).
TABLE VII

Mechanics of breathing during sleep in three normal subjects

\begin{tabular}{|c|c|c|c|c|}
\hline \multirow[b]{2}{*}{ Subject } & \multicolumn{2}{|c|}{$\begin{array}{l}\text { Pulmonary } \\
\text { compliance }\end{array}$} & \multicolumn{2}{|c|}{$\begin{array}{c}\text { Mean airway } \\
\text { resistance }\end{array}$} \\
\hline & Awake & Asleep & Awake & Asleep \\
\hline & \multicolumn{2}{|c|}{ L. $/ \mathrm{cm} . \mathrm{H}_{2} \mathrm{O}$} & \multicolumn{2}{|c|}{$\mathrm{cm} . \mathrm{H}_{2} \mathrm{O} / L . / \mathrm{sec}$. } \\
\hline $\begin{array}{l}\text { E. R. } \\
\text { D. J. }\end{array}$ & $\begin{array}{l}0.238 \\
0.164\end{array}$ & $\begin{array}{l}0.179 \\
0.203\end{array}$ & $\begin{array}{l}2.18 \\
2.03\end{array}$ & $\begin{array}{l}1.48 \\
1.09\end{array}$ \\
\hline D. T. & 0.177 & 0.201 & 2.40 & 1.42 \\
\hline
\end{tabular}

2) The $\mathrm{CO}_{2}$ tension and $\mathrm{pH}$ of arterial blood and of the respiratory center are related but are not necessarily equal. At present, techniques for the measurement of intracellular $\mathrm{pH}$ and $\mathrm{CO}_{2}$ are not available.

3) Any factor which modifies the volume of ventilation may modify the ventilatory response to $\mathrm{CO}_{2}$. It has been shown by Cherniack and Snidal (15) in normal subjects that the ventilatory response to $\mathrm{CO}_{2}$ may be depressed by increasing airway resistance. Fritts, Fishman and Cournand (16) have suggested that the depressed ventilatory response to $\mathrm{CO}_{2}$ in emphysema may be related to the increased work of breathing in this disorder.

Since pulmonary compliance is not decreased and mean airway resistance is not increased by sleep, it appears that the depression of the ventilatory response to $\mathrm{CO}_{2}$ during sleep is not related to impairment of the mechanics of breathing.

It therefore seems probable that the changes in



Fig. 7. Periodic Breathing in a Normal Subject During Sleep 
the ventilatory response to $\mathrm{CO}_{2}$ during sleep represent changes in respiratory center sensitivity to $\mathrm{CO}_{2}$. Since these changes take place within seconds, it seems probable that they are mediated neurogenically.

A working hypothesis to explain the respiratory acidosis of sleep may be stated as follows: The sensitivity of the respiratory center to $\mathrm{CO}_{2}$ is dependent on, among other factors, afferent impulses coming to it from numerous areas in the nervous system. During the waking state the number of afferent impulses is relatively large, producing a brisk alveolar ventilation and resulting in a normal waking alveolar $\mathrm{CO}_{2}$ tension. During sleep, the number of impulses is decreased and the responsiveness of the respiratory center consequently decreases. The result is a decreased level of alveolar ventilation and a rise in alveolar $\mathrm{CO}_{2}$ tension until a new steady state is achieved.

The elevated alveolar $\mathrm{CO}_{2}$ tension during sleep reported here is in agreement with the findings of most previous studies $(1,2)$. Mills has reported that the elevation of alveolar $\mathrm{CO}_{2}$ tension that takes place during the night occurs as a result of a normal diurnal cycle and is independent of whether or not the subject is sleeping (17). Our finding that normal subjects kept awake at night show no respiratory acidosis differs from the results reported by Mills. It should be pointed out that Mills studied only one subject (himself) during sleep. In addition, his technique of study consisted of utilizing a Haldane tube for the determination of alveolar $\mathrm{CO}_{2}$ tensions. At various times during the night an alarm clock roused him from sleep so that a sample of expired air might be obtained. In view of the rapid changes in $\mathrm{CO}_{2}$ tensions that we have observed in the transition from the sleeping to the waking state, it is doubtful that Mills' observations can be considered as representing alveolar $\mathrm{CO}_{2}$ tensions during sleep.

Changes in the cerebral circulation have been investigated by workers in the field of sleep. It seems probable that the changes observed may be related to changes in alveolar gas tensions. Thus, the increase in cerebral blood flow and decrease in cerebral vascular resistance during sleep reported by Mangold and co-workers (18) may be accounted for by the increase in alveolar $\mathrm{CO}_{2}$ tension.

Doust and Schneider (19) have proposed a theory which ascribes sleep to cerebral hypoxia. Using the technique of ear oximetry these authors found that arterial oxygen saturation decreased progressively during the process of sleep, reaching its lowest levels during deep sleep.

In our own studies a mean decrease of $3 \mathrm{~mm}$. $\mathrm{Hg}$ in alveolar oxygen tension was found during sleep, but this decrease was not statistically significant. The shape of the oxyhemoglobin dissociation curve is such that the saturation values for highly saturated blood fall on the flat portion of the curve. Under these circumstances, even subjects who showed the greatest decrease in alveolar oxygen tension did not have a decrease of sufficient magnitude to produce arterial oxygen unsaturation. In the subject whose hemoglobin is unsaturated in the waking state the findings may be different. Because of the shape of the oxyhemoglobin dissociation curve a small decrease in alveolar oxygen tension may produce a significant decrease in arterial oxygen saturation.

At any rate, no evidence of significant arterial oxygen unsaturation was found in our normal subjects during sleep, and thus the hypoxic theory of the genesis of sleep appears to be untenable. The possibility of a marked decrease in oxygen saturation during sleep in subjects who are moderately unsaturated while awake is under investigation.

The data reported here do not in any sense define the fundamental nature of the sleeping state. They lend themselves, however, to several generalizations :

1) The basic changes associated with sleep are rapidly reversible. The rapidity of these changes suggests that neurogenic mechanisms play a decisive role in the genesis and maintenance of normal sleep.

2) Sleep does not represent a static state. The sleeping subject shows changes in the depth of sleep, the number of bodily movements (2), alveolar gas tensions, electroencephalographic patterns (11) and blood $\mathrm{pH}$.

3) Theories of the genesis of sleep based on changes in blood gas constituents are probably untenable.

\section{SUM M ARY}

Physiologic sleep in the normal subject is associated with a significant fall in total and alveolar 
ventilation, with a significant rise in alveolar $\mathrm{CO}_{2}$ tension, with a fall in $\mathrm{CO}_{2}$ production and oxygen consumption, with a fall in ventilatory response to $\mathrm{CO}_{2}$, with a fall in blood $\mathrm{pH}$, and with a considerable incidence of periodic breathing. Alveolar oxygen tension, arterial oxygen saturation, respiratory exchange ratio, and the mechanics of breathing are not significantly altered by sleep.

The $\mathrm{CO}_{2}$ retention of sleep is related to a depression of respiratory center sensitivity. The speed of onset and reversal of this depression of respiratory center sensitivity suggests that it is mediated neurogenically.

\section{REFERENCES}

1. Hastings, A. B., and Eisele, C. W. Diurnal variations in the acid-base balance. Proc. Soc. exp. Biol. (N. Y.) 1940, 43, 308.

2. Kleitman, N. Sleep and Wakefulness. Chicago, University of Chicago Press, 1939.

3. Collier, C. R., Affeldt, J. E., and Farr, A. F. Continuous rapid infrared $\mathrm{CO}_{2}$ analysis. J. Lab. clin. Med. 1955, 45, 526.

4. Bohr, C. Über die Lungenathmung. Skand. Arch. Physiol. 1890, 2, 236.

5. Methods in Medical Research, J. H. Comroe, Jr., Ed. Chicago, The Year Book Publishers, Inc., 1950, vol. 2.

6. Comroe, J. H., Jr., Forster, R. E., II, Dubois, A. B., Briscoe, W. A., and Carlsen, E. The Lung; Clinical Physiology and Pulmonary Function Tests. Chicago, The Year Book Publishers, Inc., 1955.

7. Rosenthal, T. B. Effect of temperature on $\mathrm{pH}$ of blood and plasma in vitro. J. biol. Chem. 1948, 173, 25.

8. Van Slyke, D. D., and Neill, J. M. Determination of gases in blood and other solutions by vacuum ex- traction and manometric measurement. J. biol. Chem. 1924, 61, 523.

9. Mead, J., and Whittenberger, J. L. Evaluation of airway interruption technique as a method for measuring pulmonary airflow resistance. J. appl. Physiol. 1954, 6, 408.

10. Snedecor, G. W. Statistical Methods. Ames, Iowa State College Press, 1956.

11. Tyler, H., Robin, E. D., Travis, D. M., Crump, C. H., and Morin, F. Relationship between electroencephalographic changes and alveolar gas tensions during sleep. To be published.

12. Alexander, J. K., West, J. R., Wood, J. A., and Richards, D. W. Analysis of the respiratory response to carbon dioxide inhalation in varying clinical states of hypercapnia, anoxia, and acid-base derangement. J. clin. Invest. 1955, 34, 511.

13. Gray, J. S. Pulmonary ventilation and its physiological regulation. Springfield, Charles C Thomas, 1950.

14. Winterstein, $H$. Chemical control of pulmonary ventilation. I. The physiology of the chemoreceptors. New Engl. J. Med. 1956, 255, 216.

15. Cherniack, R. M., and Snidal, D. P. The effect of obstruction to breathing on the ventilatory response to $\mathrm{CO}_{2}$. J. clin. Invest. 1956, 35, 1286.

16. Fritts, H. W., Jr., Fishman, A. P., and Cournand, A. Factors contributing to diminished ventilatory response to $\mathrm{CO}_{2}$ of patients with obstructive emphysema. Fed. Proc. 1957, 16, 41.

17. Mills, J. N. Changes in alveolar $\mathrm{CO}_{2}$ tension by night and during sleep. J. Physiol. (Lond.) 1953, 122, 66.

18. Mangold, R., Sokoloff, L., Conner, E., Kleinerman, J., Therman, P. G., and Kety, S. S. The effects of sleep and lack of sleep on the cerebral circulation and metabolism of normal young men. J. clin. Invest. 1955, 34, 1092.

19. Doust, L. J. W., and Schneider, R. A. Studies on the physiology of awareness: Anoxia and the levels of sleep. Brit. med. J. 1952, 1, 449. 